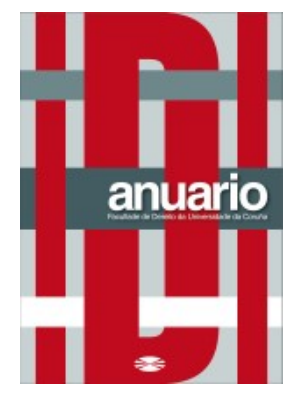

Anuario da Facultade de Dereito da Universidade da Coruña

Vol. 23 (2019), pp. 207-229

ISSNe: 2530-6324 || ISSN: 1138-039X

DOI: https://doi.org/10.17979/afdudc.2019.23.0.6017

\title{
ACTUACIONES PROCESALES DE LA MUJER EN ROMA. PROHIBICION EDICTAL Y LITERATURA JURÍDICA
}

\section{PROCEDURAL ACTIONS OF WOMEN IN ROME. PROHIBITION AND LEGAL LITERATURE}

\author{
M. ASUNCIÓN SONIA MOLLÁ NEBOT \\ Profesor Titular de Universidad \\ Universidad de Valencia ${ }^{1}$
}

\begin{abstract}
Resumen: La improcedencia moral de que las mujeres usen de la palabra en el ámbito público, que se refiere a los lugares de espacio relevante como es el forum o intervengan en actos jurídicos formales, especialmente los solemnia verba, no impide que pueda intervenir procesalmente en defensa de asuntos propios y ajenos, aunque esta postulatio se traten de virilibus officiis. De esta forma la intervención de la mujer en la defensa de asuntos propios y ajenos aparece como algo poco común pero no prohibido hasta finales de la república. Un edicto de la primera mitad del s. I a. C, introduce el impedimento general de que intervenga la mujer en los procesos ajenos. La contradictoria afirmación que prohíbe a la mujer la postulatio porque se trata de virilibus officiis, pero se permite cuando sean procesos atinentes a los intereses de la mujer.
\end{abstract}

Palabras clave: virtud, mulier, laudatio funeraria, virilibus officiis, defensa pro alii, "interés propio", postulatio.

Abstract: The moral inappropriateness of women using the word in the public sphere (forum) or intervening in legal acts by solemn words (solemnia verba) during the republican era, does not prevent them from intervening procedurally in defense of their own and others issues, since notes that except for virilibus officis there is no limitation, so that the intervention of women in the defense of their own and others issues appears as something rare but not prohibited, until the end of the republic. An edict of the classical era, s. I a. C., introduces the impediment of intervention by women in the proceedings, the contradictory allegation that it is virilibus officiis, it is maintained only

\footnotetext{
${ }^{1}$ Este trabajo se encuentra integrado en el Proyecto con núm. de Ref.: DER2016-78378-P, “La Mujer en la Literatura y la Jurisprudencia Clásicas", de la Universitàt de Valéncia (España), Depto. de Derecho Romano y Eclesiástico del Estado, concedido por el Ministerio de Economía y Competitividad, en la Convocatoria 2016 de Proyectos I+D, correspondientes al Programa Estatal de Fomento de la Investigación Científica y Técnica de Excelencia, Subprograma Estatal de Generación del Conocimiento, siendo IP's los profesores: Ma Asunción Mollá Nebot y José María Llanos Pitarch.
} 
for cases in which cases are foreign to the interests of women. It is observed that this legal succession allows to reach the defense "pro suo", that is, by itself and for its own case. The acts virilibus officiis did not change their nature to be exclusive of males, citizens, with capacity to act.

Keywords: virtue, mulier, laudatio funeral, virilibus officiis, defense pro alii, "own interest", postulatio.

Sumario: PREÁMbULO. I. PROHIBICIÓN MORAL A LA MUJER DEL USO DE LA PALABRA. II. MUJERES QUE HABLAN PÚBLICAMENTE. III. EN TORNO A LA "POSTULATIO, NEC PRO ALIO INTERVENIRE" Y MUJERES ABOGADOS. LA CUESTIÓN DE LOS “VIRILIBUS OFFICIIS”. IV. BREVE ANÁlisis DE LOS TRES CASOS QUE CITA VALERIO MÁXIMO. V. BIBLIOGRAFÍA.

\section{PREÁMBULO}

Existe un modelo de mujer en Roma que viene marcado por "la idea", más bien "el ideal" romano, que se mantiene por el arte, la reflexión filosófica, el pensamiento jurídico, y la literatura, a cerca de la virtud mulieribus ${ }^{2}$. Interesa en este trabajo concretar la realidad en los casos en que se rompe con el ideal de mujer pasiva y silente. En aras de la consecución de este objetivo resulta relevante el análisis de los datos que proporciona la literatura, también la no jurídica, incluso la iconografía, sobre estos casos concretos en los que las mujeres hablan, concretamente, la evolución hacia una apertura

\footnotetext{
${ }^{2}$ El término virtus que contiene la raíz vir (que significa hombre) se refiere a la cualidad del valor como valentía asociada a lo masculino en el pensamiento antiguo; solo la evolución del término permite relacionarlo con la mujer, pero en la sociedad clásica supone un contrasentido el uso conjunto de los dos términos (virtus mulieribus), pues hace necesario llevar el significado de la expresión a una explicación no originaria de dos términos incompatibles. Así pues, para describir las cualidades de las mujeres fuera del ámbito doméstico utilizamos el término no latino "virtud". Pues hay que tener presente la limitación que contiene el término virtus, ya que incluso cuando se habla de "esas virtudes" de la mujer se hace desde la idealización masculina que de la mujer presenta, no sólo, pero sí básicamente, la literatura. Como afirma CASTRESANA, A., Catálogo de virtudes femeninas, Madrid, 1993, p. 14, "la condición femenina nace en buena medida de la afirmación expansiva del "ser masculino". Lo que veremos se reafirma en las descripciones de Valerio Máximo al referirse a la heroica actuación de una mujer dice que: "bajo su aspecto femenino esconde un alma varonil, le pusieron el sobrenombre de Andrógina", refiriéndose a Mesia Santinas, cfr. VALERIO MAXIMO, Facta et dicta memorabilia, ed. Martín Acera, Hechos y dichos memorables, Madrid-Barcelona, 1988, Lib. VIII, cap. III, I. El hecho relatado se cuenta la defensa que de sí misma hizo Mesia Santinas (77 a.C), probablemente acusada en un juicio penal -al hacerse referencia a la intervención de un tribunal con gran concurso del pueblo, es plausible la idea de que se trate de una provocatio ad populum- "...sin que ningún hombre quisiera asumir su defensa tomara ella misma su propia defensa".

He utilizado la edición de MARTÍN ACERA, VALERIUS MAXIMUS, Facta et dicta memorabilia. titulada en esta Edición, Los nueve libros de Hechos y Dichos memorables, al igual que lo hizo DIEGO LÓPEZ, en su célebre traducción: Diego López, Valerio Máximo, Los nueve libros de los exemplos, y virtudes morales de Valerio Máximo, traducidos y comentados en Lengua Castellana por Diego López, Maestro en Latinidad y Letras Humanas, Imprenta Real, Madrid, 1655.

La edición de Martín Acera contiene una introducción general muy extensa que es de gran utilidad para entender la ubicación temporal de Valerio Máximo, su gran influencia en la retórica como libro de enseñanza.
} 
progresiva de presencia de la mujer en la intervención de procedimientos civiles; incluso en lo que hoy llamaríamos actos administrativos ${ }^{3}$. Junto a la progresión de la mujer que se inicia más activamente en la sociedad y que muestra su punto álgido en la época de Claudio, se da un momento de involución entre finales del s. I a. C, y mediados del s. I. a través de limitaciones y prohibiciones. Así, el Senadoconsulto Veleyano que prohíbe la intercessio, próximo temporalmente al Edicto de prohibición de la actuación de la mujer en el seguimiento de procesos como advocati (pro alio intervenire $)^{4}$, se presentan como medios de protección de los intereses y defensa del patrimonio de la mujer, cuando en realidad suponen una exclusión, más perjudicial que beneficiosa. La prohibición de intercessio produjo la exclusión del mundo de la fianza personal que forma parte del entramado de las relaciones mercantiles ${ }^{5}$, mientras que una suerte de explicaciones más retóricas que convincentes está en la base de la limitación de postulare pro alio intervenire.

Puede decirse que existe una sucesión en el tiempo respecto de la "no intervención de la mujer oral y pública", en el campo procesal, que responde al siguiente esquema: 1) Cumplimiento de un deber moral; 2) trasgresión de ese deber moral frente a uno superior de cumplimiento de un deber de equidad; 3) los casos en los que la no prohibición moral estuvo seguida de una prohibición jurídica; y 4) la consecuencia final de una aceptación a favor de la intervención de la mujer para actos de postulatio y seguimiento de casos ante un tribunal cuando es en interés propio. Este es también el esquema que sigue el presente trabajo.

\section{PROHIBICIÓN MORAL A LA MUJER DEL USO DE LA PALABRA}

La imagen usual de la mujer en las artes, la literatura y la iconografía romana, la simbolizan con valores relacionados con un cometido restringido al ámbito privado ${ }^{6}$. En general las representaciones artísticas como los mosaicos (musiva) y las pinturas murales que se conservan, eran comunes las imágenes de figuras mitológicas encarnando estos atributos femeninos, ofreciendo una imagen visual ligada a estos rasgos de virtud de la matrona ${ }^{7}$. Realmente no existen virtudes domésticas, sino

\footnotetext{
${ }^{3}$ No podemos hablar propiamente en derecho romano de un procedimiento administrativo autónomo, pero sí de actos administrativos en el sentido de seguimiento que se mantienen por los ciudadanos (también de los munícipes) de las obligaciones y relaciones jurídicas, respecto de los municipios o la Urbs. Ha de tenerse en cuenta que se trata de una regulación de actos jurídicos no deslindada en cuerpos legislativos de los que recogen los actos procesales comunes, como es la Lex iudiciorum privatorum (17 a. C.); también hay que tener en cuenta la limitación en derecho romano en el reconocimiento de la personalidad jurídica. Para estas cuestiones, vid. MOLLÁ-LLANOS, "Regulación Urbanística de Edificaciones Privadas: Aspectos Legales”. Iura: rivista internazionale di diritto romano e antico, n ${ }^{\circ}$ 63, 2015, pp 59 a 99.

${ }^{4}$ Es evidente que están completamente apartadas de la actividad jurisprudencial (respondere, agere, cavere), y cuando se dice que pueden intervenir "en todas las partes del proceso", como vemos en VALERIO MAXIMO, Facta et dicta memorabilia, ed. Martín Acera. Hechos y dichos memorables. cit. Madrid-Barcelona, 1988, Lib. VIII, cap. III, 1, en realidad solo puede constatarse en las palabras de Valerio Máximo, y en relación con una posible causa penal: "Habiendo sido acusada Mesia Sentinas defendió su causa ante sus jueces...Desarrolló regularmente todas las partes de la defensa...".

${ }^{5} \mathrm{La}$ intercessio de forma stipulatoria, sería necesario que interviniera a través de representante, incluso antes de la prohibición Senatorial y las consecuentes extensiones jurisprudenciales.

${ }^{6}$ Vid. FERNÁNDEZ DE BUJÁN, A., "Reflexiones a propósito de la realidad social, la tradición jurídica y la moral cristiana en el Matrimonio Romano" (I), RGDR, nº 6, 2006, p. 5.

${ }^{7}$ NEIRA JIMÉNEZ, L., "La imagen de la mujer en la Roma imperial. Testimonios musivos”, X Coloquio Internacional de la Asociación Española de Investigación de Historia de las Mujeres: Representación, Construcción e Interpretación de la imagen visual de la mujer, Madrid, 2003. Efectivamente el autor hace
} 
cualidades casi por entero referidas a las de la matrona romana que encarna la "mujermodélica" 8 .

En este sentido, la literatura incide especialmente en la alabanza de la mujer vinculada a las virtudes domésticas: lanifica, domiseda, casta, fides, pudicitia a las que puede añadirse la de "pasividad"'. Siendo marginal la referencia a las mujeres actuantes en sociedad en general, fuera de los arquetipos mencionados, están inmersas en constante presentación dicotómica: o es modélica, y por ende creadora y atrayente del beneficio, o es impúdica, y en consecuencia causante de la desgracia familiar.

La doctrina ya había observado, ante el silencio de las fuentes sobre la mujer, que era destacable como una fuente de noticias sobre ella los panegíricos y laudationes funerarias, aunque hay que señalar que esta fuente generalmente ofrece una información poco realista dada la subjetividad que caracteriza la propia exacerbación de virtudes que implican las laudationes, pues tienden a exceder, como es sabido, las cualidades del interfecto. No obstante, queremos resaltar que, salvo escasas excepciones, no se prodigan laudationes de mujeres, tanto en forma de panegírico como en monumentos funerarios, que se refiera a virtudes fuera del ámbito doméstico ${ }^{10}$. Entre estas laudationes, como decíamos, se sigue el patrón de la mujer virtuosa, ligado a esa escasa circunscripción, incluso a la inactividad ${ }^{11}$ y dentro de la misma, la que implica un

un análisis sobre la imagen y su fin propagandístico, como ocurre en la numismática del s. I, que representa la imagen del Príncipe-emperador deificado (con la intención de personalizar una institución unificadora que desde Augusto se instaura sobre el Imperio romano reforzada con esta imagen de deidad), no solo del príncipe, sino de la familia Imperial: así, en el anverso de la moneda, la imagen de la mujer del emperador con una divisa sobre alguna cualidad propia de una matrona: pietas, pudicitia, etc. Sobre la cuestión a cerca del uso de arte con fines propagandísticos, cfr. HIDALGO DE LA VEGA, M.J., Las emperatrices romanas. Sueños de púrpura y poder oculto, Salamanca, 2012, pp. 21 y ss., viene a explicar que la necesidad de consolidación del Principado y su carácter sucesorio, instaurado por Augusto, viene acompañado con refuerzo de imágenes (como el Ara Pacis Augustae, 13 a. C), "que inaugura un tipo de monumento con expresión estatal y una novedosa forma de propaganda iconográfica", la numismática y otros medios propagandísticos, también forman parte de este modo de hacer política, vid. SANNA, V., "Il modello della matrona romana", RGDR, no 31 (2018).

8 Vid. JUVENAL, Satira $n^{\circ}$ VI “...la que no deja entrar entre sus vicos...los traídos por la obscena pecunia”, en relación con las mujeres que se dedican a la préstamo pecuniario, práctica muy extendida; SENECA, Epístola XCV, 21; Ad Helviam de consolatione, XVI, 3; MARCIAL, Epigrammata, II, 68; IV, 75; mientras que si no quiere acceder al modelo-femenino, resultan objeto de reprobación, así: MARCIAL, Epigrammata, IX, 53; CATON, De re rustica, CLII, más que un catálogo el autor traslada un modelo de perfecciones de la mujer al servicio del varón, al que no se le exige, o se considera innecesario, que tenga ninguna cualidad respecto de la mujer. Sus cualidades no son relevantes, y quizá inexigibles en el ámbito doméstico, salvo el que se refiere al genérico officium pietatis.

${ }^{9}$ PALACIOS, J., "Miradas romanas sobre lo femenino: discurso, estereotipos y representación", Asparkía $\mathrm{n}^{\mathrm{o}} 25,2014$, pp. 92-110. Contiene una bibliografía completa sobre las laudationis mulieribus.

${ }^{10}$ Una excepción a la regla vemos se recoge por MENTXAKA, R., Turia: Un ejemplo de mulier fortis romana. en Mujeres en tiempos de Augusto, Valencia, 2016, pp. 99 y ss. especialmente n. 1, con más bibliografía sobre la laudatio funeraria para mujeres en general. En particular se resalta en el caso de la llamada Turia, el hecho de tratarse no de las comunes virtudes de una matrona, que ya hemos señalado arriba: lanifica, domiseda, casta, fides, pudicitia, sino de las excepcionales que se destacan aquí como mujer fuerte.

${ }^{11}$ La dualidad entre perfección-abominación, es una constante en la literatura romana, lo que se llama mujer - modelo, frente a lo que podría calificarse de mujer merecedora de todo oprobio; para este análisis cfr. CASTRESANA, A., Catálogo de virtudes femeninas, cit., pp. 22 y ss., especialmente el capítulo 3 dedicado a La "Feminidad ideal" en la literatura latina. La visión de la mujer también estuvo cargada de subjetividad negativa en la literatura griega en dónde se la representa como causa y origen de grandes males - Pandora o Helena, por ejemplo_-, o simplemente de desaprobación en términos que llegan a ser claramente arbitrarios. Las fuentes literarias, tanto griegas como romanas, centradas en la historia política 
respetable silencio ${ }^{12}$. Pocas veces nos encontramos con laudationes de mujeres que se refieran a virtudes fuera del ámbito privado. La singularidad de estas laudationes las hace especialmente interesantes. Así ocurre con una mujer llamada Turia, objeto de una laudatio en donde se describe como una mujer fortis ${ }^{13}$. Efectivamente, resalta en el caso de la llamada Turia, el hecho de tratarse no de las comunes virtudes de una matrona, que ya hemos señalado arriba (lanifica, domiseda, casta, fides, pudicitia), sino de las excepcionales que se destacan aquí como mujer fuerte. Esto se manifiesta en: la reclamación del testamento del padre muerto; la denuncia y persecución de los asesinos de sus padres (lo que entraña el ejercicio de actuaciones jurídicas encaminadas a la obtención de justicia, necesariamente a través de terceros, dada la limitación que la mujer tiene de entablar un procedimiento penal); y la protección y ocultación de su propio marido con riesgo de su vida en la época de las proscripciones de finales de la república ${ }^{14}$.

La sociedad romana, o mejor, "el juicio moral" que se contiene en los pronunciamientos de la literatura clásica romana, asumen la sublimación de la mujer silente. Pero "callar" para la mujer no es sólo una virtud modelo de mujer discreta, sino la prolongación de la prohibición moral de hablar públicamente en lugares reservados al pronunciamiento político, ya sea en el foro, infranqueable para las mujeres ${ }^{15}$, ya en los

de Roma están escritas por hombres (a excepción de AGRIPINA LA MENOR, Memorias. que debieron ser de gran importancia, pero están desaparecidas). Sobre este enfoque de los dos arquetipos dicotómicos, virtud-desdicha, cfr. HIDALGO DE LA VEGA, M.J., Las emperatrices romanas. Sueños de púrpura y poder oculto, Salamanca, 2012, recensión de ESCLAPÉS CASTELLANOS, R., Asparkía, 2014, p. 240: "Entre las mujeres imperiales hay una división entre "mujeres virtuosas" y "mujeres infames", división que, naturalmente, está determinada por "las fuentes". Las mujeres virtuosas ejercían su influencia política dentro de los valores tradicionales propios de la mujer, de modo que no resultaban peligrosas. Tales fueron Livia, Octavia, que actuaron en función de los intereses de Augusto. O Plotina y Sabina, cuyos comportamientos celebran con entusiasmo algunos autores como Plinio. Eran "infames", por el contrario, las dos Julias, Agripina la Menor, Mesalina, Popea y Domicia Longina, por su proceder autónomo y su atrevida sexualidad". Mantener el estudio de la realidad nos muestra a la mujer de otra forma; realidad que se refleja en la literatura, incluso cuando reprueba los actos en los que se describe actuaciones de mujeres, que podíamos denominar de usos y costumbres cotidianos, y que podemos también concluir tanto de textos propiamente jurídicos, como de lo que la doctrina romanística denomina textos literarios, que contienen información de la realidad común en esta sociedad que se inserta en la idea política del Imperio Romano.

${ }^{12}$ FINLEY M.I., Aspects of Antiquity. Discoveries and Controversies, London, 1968, pp. 129 y ss. Así, la alabanza del silencio se representa en la deificación de Lara o Lala, convertida en la diosa al arrancarle Jupiter la lengua. Se presenta como el modelo femenino a imitar. Lala antes había sido quizá una ninfa a la que le gustaba hablar en demasía, cfr. HÖBENREICH E. - RIZZELLI G., Fragmente einer juristischen Geschichte der Frauen im antiken Rom, Wien - Köln, 2003, pp. 71-72.

${ }^{13}$ Una excepción a la regla vemos se recoge por MENTXAKA, R., "Turia: Un ejemplo de mulier fortis romana", en Mujeres en tiempos de Augusto, cit., pp. 99 y ss. especialmente n. 1, con más bibliografía general sobre la laudatio funeraria para mujeres.

${ }^{14}$ Vid. MOLLÁ, M. A., “Actos administrativos de la mujer en la época tardo republicana”, RGDR, n² 29 , 2017. Donde se trata la cuestión de la persecución de finales de la república y el triunvirato, que devino en una diáspora de hombres que huyen de las represalias y de la situación en que quedan sus hijos y mujeres en la Urbs, con la necesidad de que éstas se inicien en una actividad comercial de mantenimiento del patrimonio familiar, y se conviertan en el motor para la supervivencia de la propia familia.

${ }^{15}$ La idea del silencio como realce de lo femenino es constante y anterior a Roma, vid. GARRIDO, M., "Voces del silencio", en CIRCE, de clásicos y modernos, no 3, 1998, pp. 74 y s., señala: "La obediencia exigida a la mujer en la antigüedad se presenta como un problema y los trágicos vuelven una y otra vez sobre esta cuestión ofreciendo a los personajes femeninos un lugar en el ámbito público de la escena, transgrediendo la norma social de una época que dictaminó que el mejor adorno de la mujer es el silencio", el gineceo es un lugar propio de un tipo de palabras ajenas al logos, mientras que el debate e intercambio de las ideas está fuera de la polis. La autora, recurre para explicar la trascendencia de la 
lugares de ámbito político fuera de Roma. Este lugar público se refiere tanto a los lugares propiamente designados como núcleo político (dentro del forum, donde se sitúa el comitium $)^{16}$, como a los actos formales que se desarrollan y que tienen relevancia jurídica formal, es decir: los solemnia verba. Por tanto, la mujer no debe intervenir en lugares reservados a la palabras de quienes se exponen públicamente ${ }^{17}$, especialmente el de un cargo político; ni tampoco en los jurídicamente trascedentes actos formales mediante palabras solemnes.

Esta prohibición que deviene de la costumbre sufrió una evolución propia, consecuencia de la liberación de las formalidades, tanto por el desarrollo mercantil, en el que de modo exponencial empiezan a intervenir las mujeres desde mediados del s. I a. C. ${ }^{18}$, como por el relajamiento general de las formalidades, y en consecuencia, de los actos formales jurídicamente relevantes, coincidente en el tiempo con el anterior, pero consecuencia del decaimiento de las formas Así: el recurso a la simple traditio, cuya naturaleza viene a desplazar a los actos de trasmisión formal de la propiedad, el apogeo de una actividad crediticia carente de formas (salvo para la fianza); y el desarrollo de los contratos, con un régimen mucho más flexible y de derecho de gentes. En este clima se produce una influencia de la expansión del comercio y la mayor intervención de las mujeres en éste ${ }^{19}$.

\section{MUJERES QUE HABLAN PÚBLICAMENTE}

Son especialmente relevantes aquellos casos en los que la mujer se pronuncia y habla públicamente; lo que se nos muestra como una actitud iconoclasta frente al proceder virtuoso que se presume a su silencio. La literatura ofrece un perfil nada homogéneo sobre la consideración que merecen las intervenciones orales públicas de las mujeres, que en unos casos son reprobadas, precisamente por hacer uso de la palabra en lugar público; y en otros ensalzadas, pero no como virtud propia, sino como virtud masculina que les ha sido prestada, como dice Valerio Máximo: "bajo su aspecto femenino escondía un alma varonil”"20, pues el hablar en público es un acto de poder.

\footnotetext{
trasgresión de la mujer que habla públicamente en la Grecia de Sófocles a la obra; Antígona, y dice: "surge Antígona de Sófocles. En esta tragedia, precisamente Ismene es la única mujer que permanece viva después de haber hecho uso de su palabra". Al respecto cfr. OBARRIO, A., Iura et Humanitas Diálogos entre el Derecho y la Literatura, Madrid, 2017, pp. 69 y ss.; especialmente respecto del silencio femenino, n. 312.

${ }^{16}$ El foro es un lugar abierto, a diferencia de la Curia donde se reúne el Senado que es un lugar cerrado, situado en la parte norte del mismo foro. El foro fue reformado sucesivamente y monumentalizado, elevado su nivel un metro por Augusto manda construir una especie de tribuna para los oradores: este es el ámbito público para los discursos y pronunciamientos políticos, prohibido a las mujeres, vid. CONNOLLY, La Ciudad Antigua. La vida en Atenas y Roma clásicas, Oxford, 1998, trad. Ripollés y Cifuentes, Madrid, 1998, pp. 111 y ss. También la realización de los juicios civiles se hace en un lugar público, abierto al aire libre y designado para cada ocasión, normalmente a las puertas de algún templo que las partes ante el Pretor acuerdan, hasta que se hizo común el procedimiento cognitorio y se realizan en un lugar expresamente dedicado a este cometido.

${ }^{17}$ La limitación a estos lugares políticos no es exclusiva del mundo romano, es también común en Grecia, vid. supra, n. 13.

18 Vid. RODRÍGUEZ R., La mujer en el mundo laboral en la antigua Roma, Madrid, 2013, pp. 250 y ss.; sobre El trabajo femenino: una realidad frente al modelo de mujer en la antigua Roma. Señala precisamente la recurrente referencia en las fuentes en las que aparece en la actuación mercantil a través de terceros.

${ }^{19}$ BARREIRO MORALES, “La situación jurídico-histórica de la mujer romana”, RGDR, no 31 (2018).

${ }^{20}$ VALERIO MAXIMO, Facta et dicta memorabilia. ed. Martín Acera, Hechos y dichos memorables. cit., Lib. VIII, cap. III, 1 "Sobre las mujeres que se defienden a sí mismas o a otras personas, ante los
} 
Toda la simbología que viene a destacar el arte y la literatura es que la virtud de la mujer está encarnada en actos que quedan en el ámbito de lo privado en la familia. Por tanto, los actos de intervención pública, es decir, aquellos en que la mujer habla, ya sea en el foro, ya sea en el ámbito procesal, que son el campo de nuestro interés, son actos al margen de la costumbre (mores), por lo que si la costumbre no cedió en este carácter constrictivo, deben ser considerados actos contrarios a la misma ${ }^{21}$. Desde el punto de vista de la oportunidad y conveniencia de la actuación de la mujer que habla públicamente, obtuvieron una valoración moral desigual, incluso, una reprobación que sancionaría finalmente la intervención procesal de las mujeres, salvo el caso de defensa de un interés propio.

Hay que reconocer, como señala unánimemente la literatura y doctrina jurídicas, también en los estudio trasversales, sociológicos, históricos etc. sobre la cuestión de la situación de la mujer ${ }^{22}$, que los grupos más humildes, es decir, la mayoría de las mujeres en la población estaban excluidos de la reflexión de las fuentes literarias, por otro lado, "los autores, juristas, filósofos, literatos, sugieren más que ofrecen información directa...el cuadro de la situación de las mujeres resulta poco concreto o representativo, focalizado en una gran parte de los casos sobre la clase senatorial y concretado en la ciudad de Roma"23. En todos los casos, ha de matizarse, con palabras

magistrados”. En español es célebre la traducción Diego López, Valerio Máximo, Los nueve libros de los exemplos, y virtudes morales de Valerio Máximo. traducidos y comentados en Lengua Castellana por Diego López, Maestro en Latinidad y Letras Humanas ed. Imprenta Real. Madrid 1655.

${ }^{21}$ La falta de actitud modélica de la mujer que habla públicamente es calificada de "impúdica", "carente de modestia", afirmación que resulta excesiva, y que tiene cierto relieve infamante, así, en la calificación de Valerio Máximo, la sentencia con la nota de "impúdica" sobre una mujer puede ser parte de la sentencia de divorcio, como vemos en VALERIO MAXIMO, Facta et dicta memorabilia, ed. Martín Acera, Hechos y dichos memorables, cit., Lib. VIII, cap. II, 3. Sin embargo, con este adjetivo de "impudicia" califica Valerio Máximo en el siguiente capítulo III a las mujeres que hablan, pues se defienden a sí mismas o a otras personas, ante los magistrados.

${ }^{22}$ La limitada situación de la mujer en cuanto a su relativa capacidad se basa en una constante referencia a la infirmitas sexus: vid. SOLAZZI, S., "Infirmitas aetatis e infirmitas sexus", AG, n 104, 1930, pp. 3 a 31, en Scritti di diritto romano, vol. III, pp. 357-367. 1930.= Napoli, 1960; DIXON, S., "Infirmitas sexus: womanly weakness in Roman law", Tijdschrift=The Legal History Review= Revue d'Histoire du Droit, 52, 4 (1984), pp. 343-371. La expresión infirmitas, cuyo significado es algo más agravado que la falta de determinación o firmeza del sexo femenino, desarrolla en la expansión de su sentido una amplia capacidad de minusvaloración del conjunto de las acciones de las mujeres. En las fuentes aparece como condición del ser mujer en el que se apoyan todas las limitaciones y prohibiciones. En la infirmitas se basa la prohibición para el sexo femenino de los virilibus officiis, así como: de asumir tutelas, de nec pro alio intervenire, de denunciar o acusar por algunos tipos de delitos; pero también para excluir el dolo, para justificar la ignorancia del derecho, y considerar inválido un testimonio femenino; vid. FERNÁNDEZ DE BUJÁN, A., "Testigos y documentos en la práctica negocial y judicial romana", RGDR, n 4, 2005, p. 24. Las expresiones fragilitas sexus, infirmitas sexus, sexus infirmus e imbecillitas sexus aparecen en varias fuentes jurisprudenciales, por ejemplo, en: D. 22, 6, 9 pr.: (Paulo, sing. De iuris et facti ignorantia "...quod et in feminis in quibusdam causis propter sexus infirmitatem dicitur: et ideo sicuti non est delictum, iuris ignorantia non laeduntur); D. 16, 1, 2, 3 (Ulpiano, 39 ad edictum: Decipientibus mulieribus dogma Senatusconsulti -Veleyano- non auxiliatur infirmitas enim feminarum; D. 49, 14, 18 pr. (Modestino, 2, de poenis: deferre non possunt mulieres propter sexus infirmitatem).

${ }^{23}$ HÖBENREICH, E., "Andróginas y monstruos. Mujeres que hablan en la antigua Roma", VELEIA $n^{\circ}$ 22,2005 , pp. 173-182. Sobre la vinculación de las representaciones artísticas y su vinculación a la clase socialmente más elevadas, vid. NEIRA JIMÉNEZ, L., "La imagen de la mujer en la Roma imperial. Testimonios musivos", cit., en X Coloquio Internacional de la Asociación Española de Investigación de Historia de las Mujeres: Representación, Construcción e Interpretación de la imagen visual de la mujer, Madrid, 2003, p. 77: "revela su correspondencia en el ámbito social a sectores pertenecientes a los estratos más privilegiados del Imperio; motivo evidente que limita la aplicación de las conclusiones de su 
de reprobación de Evelyn Höbenreich, que los "historiadores censuran determinados comportamientos de las mujeres, exageran, distorsionan la realidad, revelando no sólo convicciones ideológicas, sino también ánimo misógino ${ }^{24}$.

\section{EN TORNO A LA "POSTULATIO, NEC PRO ALIO INTERVENIRE" Y MUJERES ABOGADOS. LA CUESTIÓN DE LOS “VIRILIBUS OFFICIIS"}

Desde el punto de vista jurídico, la mujer como tal no está capacitada, aunque sea sui iuris, para todo tipo de actos: no es cives optimo iure, y carece de los derechos que lo integran (ius suffragii, ius honorum, ius militae, provocatio ad populum). Esta restricción también habría que añadir su exclusión de la tutela y curatela, tenidos dentro de los officia civilia vel publica, e igual impedimento le es aplicable a los actos jurídicos formales de disposición, como la mancipatio, la iniure cessio y la acceptilatio ${ }^{25}$. Así mismo, no puede denunciar o acusar por algunos tipos de delitos, pero en contrapartida de "esta limitada capacidad" se aplica para excluir el dolo, para justificar la ignorancia del derecho, y considerar inválido un testimonio femenino. Sin embargo, desde el s. IV a. C se admite por el ius gentium la realización de actos jurídicos por parte de la mujer, seguir procesos que sean consecuencia de éstos, aunque se trate de officia civilia; naturaleza de estos officia que no cambia, a pesar de haber cambiado la naturaleza admisible en la persona que los ejecuta, pues también puede ser una mujer quien actúa en una postulatio.

Estos officia civilia, como decimos, no pierden nominalmente su calificación y mantienen esta naturaleza indefinidamente. Al respecto del significado del término "officiis" de "officium", ha de recordarse el sentido que se advierte en la obra de Cicerón "De officiis" que mantiene el sentido de "deber" en cualquiera de los significados que el término pueda comprender ${ }^{26}$. Por su parte, en su obra, Handlexicon, Heuman-Seckel ${ }^{27}$, distinguen distintos significados: a) deber; b) complejo de prestaciones y servicios; c) (en general) ocupación; d) trabajos realizados por el personal perteneciente a un tribunal. Es evidente que estamos ante el significado de "deber", tal vez en sentido de obligación moral más antiguo, y que definitivamente se asienta como tal en la época de los Severos. La vinculación de alcance político, en este caso, se obtiene con esa

estudio a una esfera concreta y determinada"; al respecto, cfr. HIDALGO DE LA VEGA, M.J., Las emperatrices romanas. Sueños de púrpura y poder oculto, cit., p. 18. Presenta precisamente un aspecto de estas mujeres que pertenecen a las clases altas en relación con su dominio y poder, de las que resulta paradigmático aquel periodo que se refiere al que va desde Augusto a las dinastías Julio-Claudia. Señala, que el papel de algunas mujeres fue muy importante políticamente hablando, en realidad, pero "no está definido como poder real", el mismo término "emperatriz muy utilizado en la bibliografía actual...es inexistente en las fuentes". Así: D. 1, 3, 31: sobre la lex Iuliam et Papiam, diferencia entre el poder del Príncipe, que no está sometido a nadie, según el jurista, mientras que el poder de la "Augusta", al no ser reconocido como poder, está sometido a las leyes. (Ulp. 13 ad edict.: Priceps legibus solutus est, Augusta autem licet legibus soluta non est; Principes tamen aedem illi privilegia tribuunt quae ipsi habent).

${ }^{24} \mathrm{Vid}$. HÖBENREICH E., “Andróginas y monstruos. Mujeres que hablan en la antigua Roma”, VELEIA, $\mathrm{n}^{\mathrm{o}} 22$, pp. 173-182.

${ }^{25}$ La mujer no podía liberar al deudor de una obligación estipulatoria mediante acceptilatio sin auctoritas tutoris, así, Gai. 3, 171 (Quam is autem acceptilatio veluti imaginaia solutio sit, tamen mulier sine tutore auctore acceptilationem facere non potest, cumm alioquin solvi et sine tutore auctore posit", vid., MOLLÁ, M.-A., Extinción formal de las obligaciones verbales. La Acceptilatio, Madrid, 1993, pp. 99 a 103.

${ }^{26}$ CANCELLI, "Saggio sul concetto di officium in diritto romano", RISG, no 9, 1957-59, pp. 1 y ss.; CERVENCA, "Sul'uso del terme 'officium' nella legislazione posclásico-giustinianea", en Studi Grosso, vol. 3, 1970, p. 270.

${ }^{27}$ HEUMAN-SECKEL, "Handlexicon”, s.v. officium. 
invocación a "civilia vel publica" para los ciudadanos que los ejercen, y que es evidente viene referida a los virilibus officiis.

Con la expresión virilibus officiis parece innecesario decir que están excluidos del ámbito de intervención de la mujer lo que se refiere a estos "officia civilia vel publica". Sin embargo, como se ha señalado, hasta mediados del s. I a. C llega a admitirse de facto que la mujer actúe en el ámbito procesal, campo del que en principio estaba excluida, "no tanto por su incapacidad, como por la costumbre". Dos textos de Ulpiano, merecen atención por cuanto se mantiene la calificación de la actuación procesal de quien es abogado, y que responde a una actuación dentro de los llamados virilibus officiis, mientras se dice que la mujer no puede actuar "nec pro alio intervenire". La expresa exclusión "pro alio", permite entender que la mujer sí puede intervenir si lo hace en causa propia.

A propósito de lo anterior recoge Valerio Máximo con cierta normalidad que las mujeres actúen antes los tribunales "en todas las partes del proceso" 28 . Este cúmulo de fuentes requieren de una explicación respecto de la aparente contradicción terminológica de las fuentes y el cambio de sentido durante el mismo s. I a. C, pues aparece la prohibición, mediante un edicto para que la mujer intervenga y actúe en procesos; prohibición queda limitada a la intervención en aquellos procedimientos instados pro alii ${ }^{29}$.

Así pues, vemos que de la tolerancia se pasa a la prohibición, al menos para la intervención ante el magistrado, no porque se retome el sentido original de los officia civilia, sino porque se recurre a la limitación de los virilibus officiis ${ }^{30}$, pues como vamos a ver, el Pretor llegó a dar este edicto (primera mitad del s. I a. C), según dice Ulpiano ${ }^{31}$, poco después y como consecuencia de la asidua intervención de Caya Afrania en

28 Vid. VALERIO MAXIMO, Facta et dicta memorabilia. ed. Martín Acera, Hechos y Dichos memorables, cit., Lib. VIII, cap. III, 1, refiriéndose a Amesia Sentina, “...rea causam suam ...modosque omnes ac numeros defensionis".

${ }^{29}$ Sobre la prohibición proveniente de la actuación reprobada a Afrania, cfr. VALERIO MAXIMO, Facta et dicta memorabilia, ed. Martín Acera, cit., Lib. VIII, cap. III. 2. Es lo cierto que en el s. I a. C, tras la muerte de Carfania (o Caya Afrania, o Calpurnia), mujer del senador Licinii Bucconis, sucedida en el tercer consulado de Cayo Julio César con Marco Servilio, el Senado romano prohibió a las mujeres que postularan en juicio (vid. Ulpiano, D. 3.1.1.5: dum feminas prohibet pro aliis postulare). El argumento utilizado: el legendario gesto de Calpurnia, o Caya Afrania, hacia un juez que le sentenció en contra de su patrocinado, considerándolo como una agresión a la dignidad del Tribunal como la razón de Cafrania (reduccionismo lingüístico peyorativo con que se la designa), a fin de impedir a las mujeres actuar en sede judicial.

${ }^{30}$ No pueden ser magistrados, ni jueces, y tampoco árbitros, aunque no lo diga expresamente el texto; vid. FERNÁNDEZ DE BUJÁN, A., "Bases romanísticas del arbitraje actual. Análisis de las concordancias entre el derecho justinianeo y la legislación vigente en materia de arbitraje", RGDR, n 27, 2016, p. 13 y n. 25.

${ }^{31}$ Ulpiano (170 al 228), dista de Valerio Máximo, último tercio del s. I a. C, primera mitad del s. I, aproximadamente 100 años. La obra de Valerio Máximo se sitúa alrededor del año 30. Este moralista, antes que historiador, es contemporáneo del momento en que se da el edicto del que trata Ulpiano en D.3, 1, 1, 5. La redacción de Ulpiano en el relato de la causa del edicto es excesiva, parece influida por la naturaleza retórica de la obra de Valerio Máximo que fue de uso común en las escuelas utilizándose como exempla o documenta de retórica. Aún así, el alcance posterior y la influencia probada de la obra de Valerio Máximo, conocida y citada por los sucesores del mundo romano: Plinio el Viejo, Plutarco y Gellio, así como autores cristianos, prolonga su influencia hasta entrada la Edad Moderna, cfr. MARTÍN ACERA, Introducción, pp. 29 y 33 a 36, trad. y edit., Facta et dicta memorabilia cit; SCHNIEBS, A., y otros, Facta et dicta memorabilia. ed. Traducida. y Comentada. Hechos y dichos memorables, "Estudio preliminar", Lib. 1, Buenos Aires, 2014, pp. 23 a 28. 
diversos juicios en los que se extralimita, sin que tampoco quede muy claro en qué consiste esta extralimitación, por la que las mujeres ya no pueden intervenir pro alii ante el Pretor (es decir, en petición de acción y siguiendo los trámites procesales necesarios en el proceso). Así, se advierte que mientras se dice que el apartamiento de la mujer de la intervención pro alio lo es por tratarse de virilibus officiis, como vemos explica al final del texto de Ulpiano (D. 3,1, 1, 5 en 6 ed.), desde el principio lo que niega es que esta representación procesal y defensa pueda referirse a asuntos de terceros (nec postulare pro aliis) ${ }^{32}$.

Los términos en los que se recoge la prohibición de postulare por la jurisprudencia los vemos en dos textos de Ulpiano:

Así, Ulpiano en D. 50, 17, 2 y que procede del libro 1 ad Sabinum, mantiene que se excluyan a las mujeres de todos los oficios civiles: "Las mujeres deben mantenerse apartadas de todos los oficios civiles y públicos; y por eso no pueden ser jueces, ni ejercer ni postular una magistratura, ni intervenir por otro, ni ser procuradores":

Feminae ab ommnibus officiis civilibus vel publicis remotae sunt et ideo nec iudices esse possunt nec magistratum gerere postulare nec por alio intervenire nec procuratores existere.

Se está refiriendo a la intervención en actos civiles y públicos, esto es: ejercer como jueces, y postularse a una magistratura, y tampoco realizar actos de intercessio o representante procurator en favor terceros - lo que también tienen que ver con la prohibición general introducida por el Senadoconsulto Veleyano y la sucesiva ampliación jurisprudencial—, y las consecuencias patrimoniales deducidas de la intervención como procurator en un proceso al realizar actos de representación procesal por otros. Sobre esta limitación que introduce el Senadoconsulto Veleyano vemos se expresa Paulo, en el libro 30 de sus comentarios ad edictum: “...porque al igual que la costumbre privó a las mujeres de las funciones civiles y en la mayoría (de ellas) no vale de propio derecho lo que hacen..." ${ }^{33}$, en D. 16, 1, 1 (Nam sicut moribus civilia officia ademta sunt feminis et pleraque ipso iure non valent ita multo magis adimentu iis fuir id officium in quo non sola opera nudumque ministerium aerum versaretur sed etiam periculum rei familiaris ${ }^{34}$ ); o D. 5, 1, 12, 2 (Ulp. 9 ad edic.: ...non autem omnes iudices dare possunt ab his qui iudicis dandi ius habent... Moribus feminae et servi non qui nos habent iudicium, sed quia receptum est, ut civilibus officiis non fungantur). Paulo, atribuye a las costumbres: “... no todos los individuos pueden ser nombrados jueces por aquellos que tienen poder para nombrar juez, pues algunos están impedidos por la ley,

\footnotetext{
${ }^{32}$ RODRÍGUEZ-ENNES, L., "La larga lucha hacia la igualdad femenina”, AFDUDC, no 11, pp. 839 y ss.

33 Seguimos la traducción de LEÓN MESCUA, P., en https://magisterhumanitatis/derechoromano/digesto-de-justiniano/digestolibro5017dediversisregulisiuris, que introduce a nuestro juicio una interesante variante.

${ }^{34}$ La última parte del texto: "sed etiam periculum rei familiaris", la omite Hol, como vemos anota en la edición traducida del Digesto, García del Corral, sin embargo ha de destacarse que esta misma aclaración sobre el perjuicio económico al patrimonio con la designación de rei familiaris a la que se alude, puede resultar originariamente no genuina, pero está latente en la explicación conjunta del origen y ampliación jurisprudencial del Senadoconsulto Veleyano, según vemos en D. 16, 1. Esta explicación no es óbice para entender que alrededor de esta aparente protección hay una exclusión práctica de la intercessio como fiadora, pero que repercutió negativamente en la situación de prestataria, no sólo en la posición de fiadora (intercessio).
} 
otros por la naturaleza y otros por las costumbres; ...por las costumbres, las mujeres y los esclavos, y no por carecer de juicio, sino porque está admitido que no puedan desempeñar funciones civiles".

Por lo que ahora nos interesa, que es la intervención procesal, sólo nombra el supuesto claro de exclusión para un reducido campo de actuaciones, pero no se impide la defensa de la mujer en procesos en interés del propio.

En otro texto de Ulpiano, sobre la explicación del edicto, y que se recoge en sus comentarios ad edictum, libro 6, que se refiere al nombramiento de abogado, título 1 del libro 3 del Digesto, se dedica el parágrafo 5 a la prohibición para abogar por otros; se refiere especialmente a la prohibición de las mujeres a la postulatio procesal por aliis, es decir, actuar como abogado en la parte probatoria (D. 3. 1. 1. 5):

Secundo loco edictum proponitur in eos, qui pro aliis ne postulent: in quo edicto excepit praetor sexum et casum, item notavit personas in turpitudine notabiles. sexum: dum feminas prohibet pro aliis postulare et ratio quidem prohibendi, ne contra pudicitiam sexui congruentem alienis causis se immisceant, ne virilibus officiis fungantur mulieres. Origo vera intructa est a Carfania improbissima femina quae inverecunde postulans et Magistratum inquietans causam dedit Edicto...

Como vemos, Ulpiano señala que la causa de la prohibición “...proviene del caso de Carfania, una mujer muy descarada, que, al actuar sin pudor como abogada e importunar al magistrado, dio motivo a este edicto". En este edicto emanado para proveer la prohibición especial de "que pueda abogar una mujer" debió de ser poco anterior al año 48 a.C. momento de la muerte de Caya Afrania, acrónimo de Carfania ${ }^{35}$.

Cabe destacar, que la exposición del libro III del Digesto bajo el título: $L a$ defensa de los abogados, en donde se encuentra enmarcado el texto que nos ocupa, es un intento de dotar de orden sistemático a las causas por las que se da la prohibición de "abogar" establecidas por el pretor. Así, contiene en principio, exclusiones por razón del sexo y de algunos defectos, y también se extiende la prohibición a las personas señaladas por la nota de infamia. Dejando aparte este supuesto de pena aneja por infamia, se matiza la exclusión, pues como hemos visto, esta actuación de una mujer que "aboga" no se impide cuando se trata de la defensa del propio interés. Así pues, se propone un edicto del pretor en relación con aquellos que no pueden abogar por otros ante él, incluso cuando el adversario lo consiente ${ }^{36}$.

Lo que parece discutible, hasta contradictorio, es la explicación que aparece en la redacción del texto de Ulpiano, pues, como hemos visto en el texto, la razón de la prohibición "es evitar que las mujeres se mezclen en causas ajenas, en contra del pudor propio de su sexo, y desempeñen oficios viriles..." (ne contra pudicitiam sexui congruentem alienis causis se immisceant, ne virilibus officiis fungantur mulieres).

\footnotetext{
${ }^{35}$ VALERIO MAXIMO, Facta et dicta memorabilia, ed. Martín Acera, Hechos y Dichos memorables, cit., Lib. VIII, cap. III, 2.

${ }^{36}$ Edicto 26: D. 3, 1, 7 Quos prohibet praetor apud se postulare, omnimodo prohibet, etiamsi adversarius eos patiatur postulare, porque a los que el pretor prohíbe postular por sí, lo prohíbe en absoluto, incluso cuando el adversario consienta que aboguen. Vid. VALIÑO, E., El comentario de Gayo al Edicto Provincial, Valencia, 1979.
} 
Se encuentra en contradicción con el otro texto de Ulpiano citado con anterioridad (D. 50, 17, 2 pr.,), donde se recoge: "Las mujeres están apartadas de todas las funciones civiles y públicas, y por ello no pueden ser jueces, ni tener magistratura, ni actuar como abogadas (nec postulare), ni intervenir en representación por alguien (nec pro alio intervenire), ni ser procuradoras (nec procuratores existere). También el impúber debe abstenerse de todas las funciones civiles". El pasaje procedente del libro 1 ad Sabinum de Ulpiano:

Feminae ab omnibus officiis civilibus vel publicis remotae sunt et ideo nec iudices esse possunt nec magistratum gerere nec postulare nec pro alio intervenire nec procuratores existere. $\S 1$. Item impubes omnibus officiis civilibus debet abstinere.

Así pues, la referencia que en el primer texto (D. 50, 17, 2 pr-1) se hace a que esta prohibición se produce lo es como consecuencia de tratarse de un officiis civilibus vel publici, en los que las mujeres no deben quedar inmersas contra la pudicitiam de su sexo. No parece que pueda refrendarse con el otro texto, también de Ulpiano, en D. 3, 1, 1,5 que se refiere a la prohibición de los actos virilibus officiis, referencia que no parece absolutamente genuina, o al menos se percibe poco exquisita, pues incurre en una contradicción intrínseca evidente: así, mientras que se refiere a los officiis civilibus vel publicis $^{37}$, como causa de la histórica prohibición (remotae sunt) parece que por esta razón también debería estar prohibida la intervención de la mujer pro se, para la propia defensa, si de lo que se trata es de la naturaleza del acto, pues en ambos casos estamos ante un acto dentro de los llamados virilibus officiis (D. 3, 1, 1, 5). Así pues, la descripción de Ulpiano ha de matizarse, puesto que vemos no existe prohibición para la defensa en nombre propio ( pro suo), sino para el caso de que esta actuación sea en nombre de terceros (prohibet pro aliis postulare). Esto viene a limitar, en parte, las razones que aparecen en el otro texto, también de Ulpiano, D. 3, 1, 1, 5. Así pues, los dos textos conjugados ofrecen una idea matizada a cerca de la prohibición de intervención de la mujer, cuya referencia a los officiis virilibus decae, al reconocer que la prohibición sólo alcanza la intervención de la mujer pro aliis, cuando se mezcla en causa ajenas "contra el pudor de su sexo" (pudicitiam sexui congruentem alienis causis se immisceant, ne virilibus officiis fungantur mulieres).

Al final del texto D. 50, 17, 2 pr. Vemos una capacidad jurídica de la mujer, con una limitada capacidad de obrar, que Ulpiano asemeja a la situación de los impúberes (Item impubes omnibus officiis civilibus debet abstinere), y que en el caso de las mujeres quedaba restringida a los actos procesales en los que entraban en juego un

\footnotetext{
${ }^{37}$ El término officum, se encuentra a medio camino entre la obligación y deber moral. Vid. MOLLÁ, M. A., Iudex unus. Responsabilidad judicial e iniuria iudicis, Madrid, 2010, p. 54, "el officium con el significado de deber se asienta definitivamente a partir de los Severos, y con él se explica la función de un magistrado o de un funcionario, aunque existe unanimidad en admitir el carácter arcaico de los officia, que incluso algún autor ha señalado anteriores en el tiempo al propio ordenamiento político, vid. KASER, Das Römische Zivilprocesserech, München, 1966, p. 275; MURGA, Derecho Privado Romano II. El proceso, Zaragoza, 1980, p. 6, donde dice: "El officium se presenta como un curioso deber que no llega a ser nunca ni jurisdiccional, ni puramente jurídico". Estos deberes familiares o cuasifamiliares llegan a configurarse como auténticos derechos y obligaciones, manteniendo su carácter moralizante y meta jurídico".
} 
asunto ajeno, es decir: sí puede actuar por sí misma en la reclamación de derechos e intereses, sin tutor, u otro representante ${ }^{38}$.

Así, en la época clásica (primera parte del s. I) hay un reconocimiento de que las mujeres actúan frecuentemente "desarrollando todas las partes del proceso" 39 . La aseveración de Valerio Máximo (Facta et dicta memorabilia, Libro VIII, cap. 3: Sobre las mujeres que se defendieron a si mismas y a otras personas, ante el magistrado, ha de matizarse, puesto que estamos ante una obra literaria, de carácter moralista en ensalzamiento de la persona de Augusto, que trae ejemplos explicativos cuya licencia no tiene porque entrar, como ocurre ahora, en todo el rigor procesal de la citación, personación ante el pretor y seguimiento de un proceso, y de todo procedimiento.

Por razón de materia está excluida la mujer por sí misma en la apertura de los juicios penales: provocatio ad populum. Mientras que, para los juicios civiles, ante un iudex unus, lo está para todas las medidas de aseguramiento de la personación, desde el vadimonium o promesa de comparecencia ante el pretor (para el caso del demandado) y las consiguiente cautio iudicaum solvi; a las que paralelamente, en caso de ser demandante, habría de asegurar la indemnización de demanda infundada mediante el iusiurandum calumniae. En todo caso, es posible recurrir a un representante procesal (cognitor o procurator), pero no lo podría ser tampoco una mujer. Por tanto, cuando se habla de la intervención de la mujer en un procedimiento parece que habría que excluir propiamente la postulatio, en el sentido propio de "petición de acción", y circunscribirlo a la defensa y práctica de la prueba en la fase apud iudicem. Pues las limitaciones propias de la fianza mediante stipulatio, aunque dependa del aseguramiento de terceros mediante cautiones, hacen improbable una personación desde el inicio del proceso.

Esta limitación es compatible con la intervención negocial, tanto de la que se admite desde el s. IV a. C, como la más evolucionada, de la que nos habla Gayo, en la que vemos aparece una progresiva supresión de la intervención del tutor para los actos comerciales no formales, aún así, es frecuente la asistencia de un varón (incluso puede tratarse del propio hijo) para los actos jurídicos no negociales.

Aun así, Gayo 1: “...pues las mujeres de plena edad realizan los negocios por sí mismas, y en algunos casos el tutor interpone su autoridad por pura fórmula...". Lo que viene a decir es precisamente que existe una notable autonomía de las mujeres en los negocios, aunque se siga requiriendo la auctoritas tutoris para algunos casos, se recurre a esta auctoritas por necesidad formal cuando no se trate de procesos, carácter

\footnotetext{
${ }^{38}$ Hay una semejanza llamativa con el derecho positivo español, donde en algún caso se invoca "propio interés", como razón que permite la intervención en la reclamación de derechos para los menores de edad, a los que el derecho administrativo español permite intervenir siempre que se trate de la defensa de los propios intereses y derechos, aunque no alcance por razón de edad la capacidad de obrar que establece el Código Civil. Así sucede con lo dispuesto en el art. 3 de la Ley de Procedimiento administrativo común: “A los efectos previstos en esta Ley, tendrán capacidad de obrar ante las Administraciones Pública...b) "Los menores de edad para el ejercicio y defensa de aquellos de sus derechos e intereses" cuya actuación esté permitida por el ordenamiento jurídico sin la asistencia de la persona que ejerza la patria potestad, tutela o curatela. Se exceptúa el supuesto de los menores incapacitados, cuando la extensión de la incapacitación afecte al ejercicio y defensa de los derechos o intereses de que se trate. En ambos casos se recurre a un principio de "propio interés", que es latente en el caso de la mujer para el derecho romano y explícito en el caso del derecho positivo al que se refiere el artículo 3 de la LPAC. Curiosamente ambos casos están recogidos bajo el mismo grupo que nombra Ulpiano en D.50, 17, 2 pr. -1.

${ }^{39}$ Vid. supra, n. 28.
} 
del que carecen los rescripta ${ }^{40}$ Volterra y Huchthausen, tratan de un número importante de actuaciones de mujeres que se habían dirigido a la Cancillería con causas y en petición de responsa, pero referido en la última época clásica, y principios de la posclásica. Es evidente que este incremento tan notable respecto de la primera etapa clásica, es un desarrollo natural de la normalización de la capacidad de obrar, pero también del cambio e incremento de las relaciones mercantiles, que viene a recurrir por su naturaleza, a los actos de apropiación posesoria, y cada vez menos a los actos de trasmisión formal de la propiedad. Así pues, los actos civiles (formales) progresivamente desaparecen, como la mancipatio; y a la desaparición de algunos de ellos se suma la de la relajación de las formalidades de los actos solemnes ${ }^{41}$. Todo ello redunda en el reconocimiento de mayor autonomía de la mujer que se plasma en la ingente cantidad de rescripta que emanan de la Cancillería fundamentalmente desde finales del siglo II a la primera parte del s. III (entre Adriano y Diocleciano), si bien, ello como venimos viendo, no tiene reciprocidad en orden de importancia respecto de una intervención directa como advocati. Estos rescriptos, como se ha señalado, tratan de todo tipo de cuestiones, desde derechos reales, a obligaciones, familia y sucesiones, pero también, como ya hemos visto en otros sitios, las mujeres desarrollan todo tipo de negocios: como mutuantes, constructoras de naves, comerciantes de materias diversas ${ }^{42}$, y como parte contractual frente al fisco. Evelyn Höbenreich, señala al respecto que de 2.500 rescriptos que corresponden a esta época, casi 600 , son impulsados por mujeres ${ }^{43}$. En todo caso, ello no constata sino que sean sujetos activos o pasivos en una relación jurídica que se ha sometido al scriptum de la Cancillería Imperial.

Así pues, se produce un cambio progresivo de estas limitaciones civiles y públicas, ya que si en principio en los actos propios de disposición formales había de estar asistida por un tutor mulieris. Gayo revela la real situación que en el s. II, esta asistencia del tutor mulieris es irrelevante, ya que el papel del tutor del que hablamos en el primer apartado, con el paso del tiempo se convirtió en un aspecto puramente formal que tenía poco o ningún valor en la práctica, así Gai., 1, 190:

"Pero para que las mujeres de plena edad estén en tutela, ninguna razón puede convencer suficientemente; pues lo que vulgarmente se cree, de que es justo que sean gobernadas por la autoridad de los tutores, debido a que están frecuentemente expuestas a engaño por su ligereza, resulta una razón de más apariencia que de verdad; pues las mujeres de plena edad realizan los negocios por sí mismas, y en algunos casos el tutor

\footnotetext{
40 De los rescriptos sólo tenemos constancia de su salida de la Cancillería, pero no de que sean necesariamente aplicados a las resoluciones judiciales y formen parte de un proceso, esta perspectiva es sostenida por parte de la doctrina entre los que se encuentran PALAZZOLO, Poter imperiale ed organi giurisdizionali en el II secolo d. C., Milano, 1974; D’ORS, A., Rescriptos y Jurisdicción extraordinaria, 1977.

${ }^{41}$ La convertibilidad de los actos formalmente inadecuados, empieza a admitirse a finales del s. I, como lo corrobora el Senadoconsulto Neroniano y, es posible que desde Juliano, también fueran convertibles las acceptilationes inutilis. Aún así, parte de la doctrina, mantiene la convertivilidad para un momento jurisprudencial anterior, con Sabino, cfr. PERNICE, Labeo A., Tübingen, 1963, p. 406. Mientras que GIUFFRÈ, "Convalescere in Gai 2, 218”, en Synteleia Arangjo Ruiz, vol. 2, p. 627, n. 17, cree que la técnica de la conversión había sido elaborara por Papiniano, Paulo y Ulpiano. En nuestra opinión, la posibilidad de conversión de los actos inutilis dependería de que tal tipo de actos fueran reconocidos por la Jurisprudencia, lo que no sucede hasta el siglo II, con Juliano; cfr. MOLLÁ, M. A., Extinción formal de las obligaciones verbales. La acceptilatio, Madrid, 1993, pp. 176 y ss.

${ }^{42}$ De esto ya hemos tenido ocasión de ocuparnos, vid. Actos administrativos de la mujer en la época tardo republicana. cit. especialmente apartado relativo II. Comercio y officia civilia vel publica.

${ }^{43}$ HÖBENREICH E., “Andróginas y monstruos. Mujeres que hablan en la antigua Roma”, cit., p. 175.
} 
interpone su autoridad por pura fórmula; y frecuentemente incluso contra su voluntad, obligado por el pretor".

Teniendo en cuenta la relativa proximidad temporal entre Gayo y Ulpiano, la aseveración gayana es más evolucionada que la teórica que describe Ulpiano en D. 50, 17, 2 pr. - 1 , lo que hace pensar que se trata de un texto poco fiable en cuanto a su entera autoría, y en todo caso poco congruente.

Respecto de las Intervenciones de la mujer en actos administrativos, hay que matizar que en esta materia administrativa son abundantes las intervenciones de mujeres, pues por su naturaleza, no requieren de las formalidades, e intervención en lugares públicos, ni del uso de palabras solemnes, y son asumidos frecuentemente por quienes no son cives optimes iure, incluso por peregrinos Este es el caso de la exención de impuestos, de la que llegan a pronunciarse los triunviros ante la manifestación de matronas y la petición pro aliis que en forma de discurso realiza Hortensia ${ }^{44}$ (año 43 a.C.). Hortensia defiende en un discurso ante los triunviros la retirada de los impuestos para 1400 matronas romanas de las que "ningún hombre se atrevía a tomar su defensa". También vemos ocurre en otras peticiones ante el Senado que redundan en reconocimientos de derechos pro aliis, como resulta el Senadoconsulto Volusiano ${ }^{45}$. Ciertamente no son actos que puedan considerarse si quiera procesales, pero sí entran en esa consideración de actos que requieren de una petición, muchas veces oral, ante el poder de los triunviros, o de la autoridad del Senado de la res publica, o de la curia en caso de los municipios y colonias ${ }^{46}$.

\section{BREVE APROXIMACIÓN A LOS TRES CASOS QUE CITA VALERIO MÁXIMO}

La obra de Valerio Máximo, Hechos y dichos memorables ${ }^{47}$, recoge uno de los pasajes más valiosos en las fuentes para tratar la cuestión de las mujeres que hablan públicamente y actúan en juicio. Pese a que se trata de una fuente literaria, en parte se encuentra refrendada por otras fuentes también jurídicas, lo que dota de enorme valor las información que contiene, y más concretamente el largo pasaje que ahora nos ocupa que se encuentra en el Libro VIII, capítulo $3^{48}$.

\footnotetext{
44 Vid. MOLLÁ, M. A., “Actos administrativos de la mujer en la época tardorrepublicana”, Revista General de Derecho Romano, n 29, 2017, pp.11 y ss.

45 Vid. MOLLÁ, M. A., “Actos administrativos y capacidad en la época tardo republicana”, en Actas del XX Congreso Internacional Ibero-Americano, Porto, 2018, pp. 641 y ss.: "La petición en favor de Alliatoria Celsilla -aun cuando no conocemos con exactitud al peticionario, y se ha especulado con que tal petición la realizara el mismo emperador-, se sitúa en el marco de los actos necesarios, en los expedientes seguidos ante el municipio por los propietarios interesados en la demolición de un edificio, que asumían la obligación de reconstrucción, actuación que en este campo no podría ser ni esporádica ni casual, como podía deducirse de la única fuente completamente identificada que era el senadoconsulto Volusiano, pues este expediente de peticiones era completamente habitual".

46 Carecemos de noticia de mujeres que se hayan dirigido a los munícipes pero no es improbable si tenemos en cuenta la naturaleza dominical del sujeto obligado frente al municipio, colonia, por el mantenimiento de los inmuebles urbanos, vid. MOLLÁ-LLANOS, "Regulación Urbanística de Edificaciones Privadas: Aspectos Legales", Iura: rivista internazionale di diritto romano e antico, $\mathrm{n}^{\circ}$ 63, 2015, pp. 59 a 99; también, supra, n. 45.

47 VALERIO MAXIMO, Facta et dicta memorabilia, ed. Martín Acera, Hechos y dichos memorables, cit.

${ }^{48}$ Los filólogos generalmente la inscriben en el género historiográfico, otros estudiosos la consideran un tratado de ética práctica, e incluso una simple recopilación de exempla destinada a quienes aprendían o practicaban las declamationes, postura sostenida por Bloomer (1992) con argumentos un tanto parciales y
} 
Más que un análisis sobre las condiciones en que se escribe esta obra literaria, y el objetivo del autor, nos interesa la visión moralista en este ejercicio de retórica, pero sobre todo, que se trate de hechos, según costumbres, que merece atención para un estudio de perspectiva jurídica. Valerio Máximo trae tres ejemplos que constituyen hitos sobre mujeres que intervienen o postulan en juicio, tanto en asuntos propios como ajenos. De ellos no se hace por el autor una censura igual, aunque el capítulo III del libro 8 de Valerio Maximo, Facta et Dicta memorabilia, comienza con un trato generalista y despectivo sobre las intervenciones de las mujeres, así, dice: "No podemos guardar silencio sobre aquellas mujeres a quienes, ni la modestia de su sexo ni las insignias de su pudor, pudo impedirles que hablaran en el foro y en los tribunales"49.

Por lo que se refiere al esquema que presenta la obra de Valerio Maximo, dice Alicia Schniebs, en Dubitatio y exemplum ${ }^{50}$ sobre el funcionamiento de la ejemplaridad que: "en la cultura romana, la ejemplaridad es un discurso". Efectivamente los símbolos cumplen una misión didáctica que organiza el pasado, y que tiene cuatro instancias: 1.una acción puntual; 2.- una lección a través de las personas que actúan como testigos de "un hecho" representativo para la sociedad; 3.- que el hecho que se inscribe en la memoria colectiva, y que sirve de precedente para "audiencias secundarias"; 4.Imitación o evitación del acto, "su trasformación en paradigmas (vicio y virtud): positivos (laus), o negativos (reprehensio) para el conjunto social ${ }^{51}$.

El aspecto más interesante es que los tres ejemplos abordan esta intervención en tres órdenes procesales distintos: 1.- (Mesia Santinas) penal; 2.- (Afrania) civil; 3.(Hortensia) Actos administrativos. Desde luego una obra literaria de las actuales características inserta y preside la valoración moral que para el autor tiene cada uno de hechos que describe, ese es el propósito final para el autor, y en esto es fiel al dicotómico juicio moral latente en la asunción de los paradigmas de vicio y virtud: virtud (laus), frente a censura (reprehensio) por estas intervenciones de mujeres que hablan públicamente, aún cuando para cada una reserva un juicio particular, en conjunto quedan bajo el título peyorativo con que se enuncia el capítulo III del libro 8; Sobre las mujeres que se defienden a sí mismas, o a otras personas, ante el magistrado. "No podemos guardar silencio sobre aquellas mujeres a quienes, ni la modestia de su sexo ni las insignias de su pudor, pudo impedirles que hablaran en el foro y en los tribunales". Siendo una auténtica declaración peyorativa global del hecho en sí de hablar públicamente, ante el magistrado, en el foro, pero de lo que se deduce, que era posible, y jurídicamente un acto válido. Sólo la prohibición posterior pudo cambiar esta eficacia jurídica a estar prohibido.

Sin embargo, como luego veremos, estas tres mujeres hablan públicamente, pero su cometido, y sobre todo, el juicio moral de su actuación, es muy distinto:

\footnotetext{
ya discutidos por la crítica. Entiendo, a pesar de las negativas críticas de la filología, que la obra contiene una virtualidad demostrada para la retórica y su permanencia en el tiempo, al menos hasta la época moderna; esta la mejor prueba de su eficacia para los estudiosos del derecho.

${ }^{49}$ Título del Libro VIII, capítulo 3.

${ }^{50}$ SCHNIEBS A., "Dubitatio y exemplum en Valerio Máximo: el funcionamiento de la ejemplaridad y la memoria en Roma", CIRCE, no 16 , pp. 85 y ss.

${ }^{51}$ VALERIO MAXIMO, Facta et dicta memorabilia, cit., 5, 2, pr.: Gratas vero animi signifi cationes et ingrata facta libuit oculis subicere, ut vitio ac virtuti iusta merces aestimationis ipsa comparatione accederet. Sed quoniam contrario proposito sese distinxerunt, nostro quoque stilo separentur, prioremque locum obtineant quae laudem quam quae reprehensionem merentur.
} 
La primera: Mesina Santinas, defiende su causa ante los jueces, al ser demandada, o probablemente acusada de un crimen, para el que no halló varón defensor; la tercera, Hortensia (año 43 a.C.) defiende en un discurso ante los triunviros en la retirada de los impuestos para 1400 matronas romanas de las que "ningún hombre se atrevía a tomar su defensa". A las dos se les distingue su acción por Valerio Máximo, asimilando su actuación a la propia de un hombre, denominando a la primera, como Andrógina virilem animun gerebat, y a Hortensia, como inspirada, casi resucitadora de su padre, el orador Quinto Hortensio. Mientras que Caya Afrania recibe las más severas palabras, llegando a denominar los dos cónsules que ejercer su magistratura en el año de la muerte de Caya Afrania (Julio Cesar y Publio Servilio), es decir, la denominación epónima propia de la designación romana de los años, "pues de monstruo semejante dice Valerio Máximo- es preciso hacer saber a los venideros más el año de su desaparición que el de su nacimiento".

Así pues, los tres textos de Valerius Maximus ${ }^{52}$ ubicados en su obra, Factorum et dictorum memorabilium (Hechos y dichos memorables), en el capítulo III del libro octavo, bajo el epígrafe: Sobre las mujeres que se defendieron por sí mismas o a otras personas, ante los magistrados. Reúnen los supuestos del postulare pro alio, y una explicación de la causa del edicto que establece su prohibición, que también conocemos por el texto de Ulpiano en D. 3, 1, 1,5 del que ya hemos tratado con anterioridad.

\section{A. Mesina Santinas (año 77 a.C.).}

De la primera, Mesina Santinas, sabemos, que "habiendo sido acusada, se defendió ante sus jueces, presididos por el Pretor, Lucio Ticio, y en medio de un gran concurso del pueblo. Desarrolló regularmente todas las partes de la defensa con talento, incluso con energía, por lo que fue absuelta en el primer juicio casi por unanimidad":

\subsubsection{Amesia Sentinas rea causam suam L. Titio praetore iudicium cogente} maximo populi concursu egit modosque omnes ac numeros defensionis non solum diligenter, sed etiam fortiter executa, et prima actione et paene cunctis sententiis liberata est. quam, quia sub specie feminae uirilem animum gerebat, Androgynen appellabant.

No se sabe qué tipo de juicio y cuál es la causa. Se ha especulado con la posibilidad de que fuera público y que se trate de una quaestio, Momsem es de opinión contraria. La referencia "a jueces", en plural, parece indicar o un tribunal de recuperatores, cuya jurisdicción es limitada, y en este caso improbable, o bien una quaestio penal en juicio público, aunque se deja en el aire y es inconcreto sobre si es por la naturaleza del asunto que nadie (varón) quiere ofrecerse a defender la causa como abogado de la defensa.

\footnotetext{
${ }^{52} \mathrm{El}$ autor, del s. I a.C., redacta esta obra al servicio de la familia Julia, aunque se especula con que los destinatarios fueron aprendices de retórica a los que se les suministra como material didáctico. Escribió a las órdenes de su patrono Sexto Pompeyo, de cuyo séquito forma parte en su camino al proconsulado en Asia. Parece que termina de redactarla en el año 31. Tiene también un marcado estilo panegírico, con una alabanza desbordada hacia Tiberio, de la que, a juicio de Martín Acera "quizá no sea del todo culpable sino por ser este el estilo propio de quien sirve a patrono", MARTÍN ACERA, F., Introducción del editor en su traducción de la obra de VALERIO MAXIMO, Facta et dicta memorabilia, Hechos y dichos memorables, cit., pp. 19 y ss.
} 
La visión que traslada Valerio Máximo, se vuelca en al apelativo con el que la define: Andrógina, en lo que se contiene la sensación de estar ante una actuación propia de un varón: "virilem animun gerebat".

El caso recuerda aquél que habíamos planteado al principio, sobre Turia (mulier fortis) como mujer fuerte ${ }^{53}$, que se pone de manifiesto en la reclamación del testamento del padre muerto, la denuncia y persecución de los asesinos de sus padres, lo que entraña el ejercicio de actuaciones jurídicas encaminadas a la obtención de justicia en el ámbito penal público, y la protección y ocultación de su propio marido con riesgo de su vida en la época de las proscripciones de finales de la república. La diferencia es que Amesia Sentinas, es la acusada, mientras que Turia se enfrenta a dos juicios penales por denuncia que promueve ella. En todo caso de Mesia Santinas, actúa por sí misma y para sí misma.

B. Caya Afrania (año 48 a. C.).

De la segunda, en cambio, se nos da una impresión negativa. Caya Afrania, esposa del senador Licinio Bucconis, "siempre dispuesta a meterse en pleitos, no porque careciese de abogados, sino porque le sobraba desenvoltura. Haciendo temblar las salas de los tribunales con gritos, cosa desacostumbrada en el foro, llegó a ser un ejemplar único de intriga femenina". Su nombre se utilizó como calumnioso apelativo para apodar a las mujeres de malas costumbres, y sólo se señala el año de su desaparición por epónimos, pues coincide con el año del nombramiento de Julio Cesar, junto a Publio Servilio (48 a.C.) $)^{54}$.

8.3.2 C: Afrania vero Licinii Bucconis senatoris uxor prompta ad lites contrahendas pro se semper apud praetorem verba fecit, non quod advocatis deficiebatur, sed quod inpudentia abundabat. itaque inusitatis foro latratibus adsidue tribunalia exercendo muliebris calumniae notissimum exemplum evasit, adeo ut pro crimine inprobis feminarum moribus $C$. Afraniae nomen obiciatur. prorogauit autem spiritum suum ad $C$. Caesarem iterum $<P$. $>$ Seruilium consules: tale enim monstrum magis quo tempore extinctum quam quo sit ortum memoriae tradendum est.

La censura absoluta a Afrania con los adjetivos: improbissima femina, inpudentia, mostrum magis, incluso el recurso literario "latratibus", "ladrar" en lugar de, quizá gritar, es extremadamente peyorativo, exagerado. Un discurso excesivo, y una consecuencia damnatio memoriae por la que sólo merece ser recordada y "transmitir a la posteridad el recuerdo del momento de su muerte que el de su nacimiento".

Ulpiano nos ofrece la razón de porque las mujeres no podían intervenir por otro, en el texto recogido en D. 3, 1, 1, 5 (Ulp. 6 ed.) y señala a Caya Afrania (con la contracción Carfania) como la causa de este edicto (...origo vero introducta est a Carfania improbissima femina, quae inverecunde postulans et magistratum inquietans causam dedit edicto).

A pesar de que se ha dicho que la denostación de Valerio Máximo responde a una ironía mal intencionada en su obra, es lo cierto que el destino más fecundo de esta

\footnotetext{
${ }^{53}$ Vid. supra, n. 9.

${ }^{54}$ La datación es por epónimos, ya que se nombra a los años por los cónsules. El añadido del año exacto no está inserto en el texto original en latín.
} 
obra es que fuera utilizada por quienes aprenden retórica; lo cierto es que, quizá, por ser una repetición entre quienes aprenden retórica, se repitiera lo mismo por Ulpiano "y casi con las mismas palabras" que leemos en el texto de Valerio Máximo. Así, al decir que esta prohibición de la defensa procesal de las mujeres pro alio, proviene del caso de Carfania, que en palabras de Ulpiano se trata de: "una mujer muy descarada, que, al actuar sin pudor como abogada e importunar al magistrado, dio motivo a este edicto". Deja entrever claramente la influencia ejercida por su inspirador; Valerio Máximo. En todo caso, ni siquiera esta descalificación excluye totalmente a la mujer de los tribunales pues el edicto del que habla Ulpiano, como hemos visto, permite que la mujer intervenga en la defensa cuando se trate de casos en que actúe en propio su interés, es decir, lo que se prohíbe es su intervención pro alio. Como hemos dicho, el estudio comparado de los dos textos se refiere a la limitación de postulare, que finalmente se trata de una intervención que no impide la postulación pro se.

Además, Carfania actuaba por sí mima sin ningún representante o procurator, pues ni Ulpiano ni Valerio Máximo hacen mención de estos. Hay una clara diferencia de estilo entre el modo no técnico de Valerio Máximo al referirse a la mujer que se defiende con su palabra pro se verba fecit, mientras que, lo adecuado sería decir que "postulaba" en una causa propia ${ }^{55}$. En todo caso, lo que revela la afirmación de que Carfania actúa en la postulatio sin procurator ni representante, es que tiene algunos conocimientos jurídicos, así como experiencia forense.

El edicto en cuestión establece que para presentar demandas ante el tribunal se distinguía tres grupos: 1) Prohibición absoluta para personas inferiores a 17 años y sordos 2) Sólo para causas propias se admitía a mujeres, ciegos, homosexuales pasivos, condenados en un proceso capital y otros infames. 3) Por causa propia y de otros (limitado a determinadas personas). Después de la emanación del edicto, por tanto, las mujeres podían postular para sí mismas, pero no para otros.

C. Hortensia ${ }^{56}$.

La tercera, Hortensia, hace un discurso en el año 43 a.C., cuando toma la palabra en nombre de 1400 matronas, a las que se grava con impuestos que vienen a mermar sus fuentes de sostenimiento: “...y no encontrando ningún hombre que se atreviera a tomar su defensa, asumió ella misma la defensa de las mujeres ante los triunviros, con coraje y feliz éxito".

8.3.3 Hortensia uero Q. Hortensi filia, cum ordo matronarum gravi tributo a triumviris esset oneratus $<$ nec $>$ quisquam virorum patrocinium eis accommodare auderet, causam feminarum apud triumviros et constanter et feliciter egit: repraesentata enim patris facundia impetrauit ut maior pars imperatae pecuniae his remitteretur. revixit tum muliebri stirpe $Q$. Hortensius verbisque filiae aspirauit, cuius si virilis sexus posteri uim sequi voluissent, Hortensianae eloquentiae tanta hereditas una feminae actione abscissa non esset.

\footnotetext{
${ }^{55}$ HÖBENREICH E., “Andróginas y monstruos. Mujeres que hablan en la antigua Roma”, cit., p. 175.

${ }^{56}$ Sobre Hortensia existe una amplia bibliografía imposible de reproducir, con todo me remito a MOLLÁ, M. A., "Actos administrativos de la mujer en la época tardorrepublicana", cit., donde se aborda como acto administrativo de exención de impuestos.
} 
Como ya dijimos en otro lugar, bien podría interpretarse "como un recurso carente de formalidades y en vía administrativa, no judicial, contra un acto administrativo de imposición de impuestos nominal; si bien la vía de imposición sea un edicto y la de la revocación que aquí vemos no tiene esa naturaleza" ${ }^{57}$. La decisión impositiva se corrige al día siguiente y se rebaja a 400 las mujeres que deben pagar impuestos por la razón y cualidad invocada. El pronunciamiento de la petición es público. Una vez más vemos que la limitación no es de pronunciamiento sino de officia publica, es decir, de actividad desarrollada. Se ha destacado por la doctrina que efectivamente no se trata de un discurso en petición de reconocimiento de derechos, puesto que no los tienen, sino que, precisamente porque no los tienen, piden la inaplicación de las consecuencias económicas del "mal uso de estos derechos en el ámbito político" $" 58$. Tiene que ver esta petición con el Senadoconsulto Volusiano, en cuanto que su alcance no es solo "el propio interés", sino el de terceros. Este senadoconsulto se pronuncia por el Senado en respuesta a la petición de Aliatoria Celsilla que obtiene el permiso de demolición sin reconstrucción y subsiguiente venta de materiales, salvando así la prohibición que impone el Senadoconsulto Hosidiano que condena y declara nula la venta de esos materiales de construcción (venta inrita). La diferencia es que la exención de impuesto que obtiene Hortensia es un beneficio directo y nominal pro alii, mientras que el Senadoconsulto requiere en cada expediente de demolición la autorización expresa de no reconstrucción, que puede discrecionalmente otorgar el Senado o la Curia municipal ${ }^{59}$.

La conclusión es que nunca fue reconocido como derecho la postulatio de la mujer, ni tampoco se reconoció una intervención pública oral, pero, sin embargo, fuera de la norma se dio desde en el periodo que media en la República y poco antes del advenimiento de Augusto el desarrollo del reconocimiento de estas intervenciones, primero ilimitadas, y luego prohibidas, consecuencia de un edicto, que solo permite la intervención "en favor de sí misma" en lo que hoy llamaríamos "actos en interés propio".

\section{BIBLIOGRAFÍA}

AGRIPINA LA MENOR, Memorias.

BARREIRO MORALES, La situación jurídico-histórica de la mujer romana, en RGDR. 31 (2018).

CANCELLI, Saggio sul concetto di "officium" in diritto romano, en RISG, 9 (195759).

CASTRESANA, A. Catálogo de virtudes femeninas (Madrid, 1993).

CATON, De re rustica.

CERVENCA, Sul'uso del terme "officium" nella legislazione posclásico-giustinianea, en Studi Grosso, 3 (1970).

\footnotetext{
${ }^{57}$ Vid. supra, pp. 2 y s.

${ }^{58}$ Vid. MOLLÁ, M. A., “Actos administrativos de la mujer en la época tardo republicana”, cit., p. 13.

${ }^{59}$ Vid, MOLLÁ-LLANOS, "Regulación urbanística de edificaciones privadas. Aspectos Legales", cit., n.
} 3. 
CONNOLLY, La Ciudad Antigua. La vida en Atenas y Roma clásicas (Oxford 1998), trad. Ripollés y Cifuentes, (Madrid, 1998).

D’ORS, A., Rescriptos y Jurisdición extraordinaria (1977).

DIXON, S., "Infirmitas sexus: womanly weakness in Roman law", en Tijdschrift =The Legal History Review= Revue d'Histoire du Droit, 52, 4 (1984).

FERNÁNDEZ DE BUJÁN, A., Testigos y documentos en la práctica negocial y judicial romana, en $R G D R, 4$ (2005);

Reflexiones a propósito de la realidad social, la tradición jurídica y la moral cristiana en el Matrimonio Romano (I), en RGDR, 6 (2006);

Bases romanisticas del arbitraje actual. Análisis de las concordancias entre el derecho justinianeo y la legislación vigente en materia de arbitraje, en RGDR, 27 (2016).

FINLEY M.I., Aspects of Antiquity. Discoveries and Controversies (London, 1968).

GARRIDO, M., Voces del silencio, en CIRCE, de clásicos y modernos, vol. 3 (1998).

GIUFFRÈ, “Convalescere” in "Gai” 2, 218, en Synteleia Arangjo Ruiz, 2.

HEUMAN-SECKEL, Handlexicon, s.v. "officium”.

HIDALGO DE LA VEGA, M.J., Las emperatrices romanas. Sueños de púrpura y poder oculto (Salamanca, 2012).

HÖBENREICH, E., Andróginas y monstruos. Mujeres que hablan en la antigua Roma, en VELEIA, 22 (2005).

HÖBENREICH E. - RIZZELLI G., Fragmente einer juristischen Geschichte der Frauen im antiken Rom (Wien - Köln, 2003).

JUVENAL, Sátira VI.

KASER, Das Römische Zivilprocesserecht (München, 1966).

LEÓN MESCUA, P., en https://magisterhumanitatis/derecho-romano/digesto-dejustiniano/digestolibro5017dediversisregulisiuris.

LÓPEZ, D., Valerio Maximo, Los nueve libros de los exemplos, y virtudes morales de Valerio Máximo, traducidos y comentados en Lengua Castellana, Imprenta Real (Madrid 1655).

MARCIAL, Epigrammata. 
MENTXAKA, R., Turia: Un ejemplo de mulier fortis romana, en Mujeres en tiempos de Augusto (Valencia, 2016).

MOLLÁ, M.-A., Extinción formal de las obligaciones verbales. La "Acceptilatio" (Madrid, 1993);

Iudex unus. Responsabilidad judicial e iniuria iudicis (Madrid, 2010);

Actos administrativos de la mujer en la época tardorrepublicana, en, Revista General de Derecho Romano 29 (2017);

Actos administrativos y capacidad en la época tardo republicana, en Actas del XX Congreso Internacional Ibero- Americano (Porto, 2018).

MOLLÁ-LLANOS, Regulación Urbanística de Edificaciones Privadas: Aspectos Legales, en Iura: rivista internazionale di diritto romano e antico 63 (2015).

MURGA, Derecho Privado Romano II. El proceso (Zaragoza, 1980).

NEIRA JIMÉNEZ, L., La imagen de la mujer en la Roma imperial. Testimonios musivos, en $X$ Coloquio Internacional de la Asociación Española de Investigación de Historia de las Mujeres: Representación, Construcción e Interpretación de la imagen visual de la mujer (Madrid, 2003).

OBARRIO, A., Iura et Humanitas Diálogos entre el Derecho y la Literatura (Madrid, 2017).

PALACIOS, J., Miradas romanas sobre lo femenino: discurso, estereotipos y representación, en Asparkía, 25 (2014).

PALAZZOLO, Poter imperiale ed organi giurisdizionali en el II secolo d. C. (Milano, 1974).

PERNICE, Labeo A (Tübingen, 1963).

RODRÍGUEZ R., La mujer en el mundo laboral en la antigua Roma (Madrid, 2013).

RODRÍGUEZ-ENNES, L., "La larga lucha hacia la igualdad femenina” en AFDUDC, 11 (A Coruña, 2007).

SANNA, V., Il modello della matrona romana, en $R G D R, 31$ (2018).

SCHNIEBS, A., Dubitatio y exemplum en Valerio Máximo: el funcionamiento de la ejemplaridad y la memoria en Roma, en CIRCE, 16 (2013).

SCHNIEBS, A., y Otros, Facta et dicta memorabilia, ed. Traducida. y Comentada, Hechos y dichos memorables Estudio preliminar, libro 1 (Buenos Aires 2014).

SENECA, Epístola; 
Ad Helviam de consolatione.

SOLAZZI, S., "Infirmitas aetatis e infirmitas sexus" en $A G 104$ (1930) 3 a 31, en Scritti di diritto romano, v. III (1930)= ( Napoli, 1960).

VALERIO MAXIMO, Facta et dicta memorabilia, ed. Martín Acera (MadridBarcelona, 1988).

VALIÑO, E. El comentario de Gayo al Edicto Provincial (Valencia, 1979). 